УДК 550.832

\title{
ВОЗМОЖНОСТИ СКВАЖИННОЙ ТЕРМОМЕТРИИ ПРИ РЕШЕНИИ ГИДРОГЕОЛОГИЧЕСКИХ ЗАДАЧ
}

\author{
А. А. Аузин, Хеляль Марьям Ахмад \\ Воронежский государственный университет \\ Поступила в редакцию 15 февраля 2019 г.
}

\begin{abstract}
Аннотация: в статье представлены некоторые возможности скважинной термометрии, которые обычно не реализуются при проведении геофизических исследований гидрогеологических скважин. Рассмотрены возможные источники локальных аномалий температурного поля, регистрируемого в скважинах. Показано, что температурные измерения позволяют определять важсные особенности эксплуатации скважин, их конструктивные характеристики, ијелостность обсадных колонн и источники питания водоносных горизонтов. Применение скважинной термометрии в комплексе с другими геофизическими методами существенно расширяет круг решаемых ими задач.
\end{abstract}

Ключевые слова: скважинная термометрия, заколонные перетоки, гидрогеологические скважины.

\section{THE FEATURES OF BOREHOLE THERMOMETRY IN SOLVING HYDROGEOLOGICAL PROBLEMS}

\begin{abstract}
: the article presents some features of well thermometry, which are usually not implemented during geophysical studies of hydrogeological wells. Possible sources of local anomalies of the temperature field recorded in wells are considered. It is shown that temperature measurements make it possible to determine the important features of the operation of wells, their design characteristics, the integrity of the casing strings and the power sources of aquifers.

The use of borehole thermometry in combination with other geophysical methods significantly expands the range of their tasks.

Key words: borehole thermometry, annular flows, hydrogeological wells.
\end{abstract}

Скважинная термометрия представляет собой измерение температуры скважинной жидкости. На практике скважинная термометрия реализуется в двух вариантах: как метод исследования естественного теплового поля земли, носящего стационарный характер, и как метод изучения нестационарных тепловых полей, имеющих искусственное происхождение. В первом случае измерения температуры производятся в скважинах с установившимся или практически установившимся тепловым режимом. При этом измеряемым и интерпретируемым параметром является естественная температура пород, слагающих разрез скважины, а метод обычно называют геотермия $[1,2]$. По данным геотермических исследований осуществляется прогнозирование тектонического строения территории, определение областей питания подземных вод, поиски некоторых видов полезных ископаемых (горючих ископаемых, сульфидных руд, галогенных пород), расчленение разрезов скважин.
В случае реализации второго варианта скважинной термометрии, который обычно обозначается как «термокаротаж», регистрируется нестационарное тепловое поле, сформировавшееся под воздействием таких факторов как бурение скважины, её промывка, откачка или долив флюидов в скважину и пр. В данной работе рассматриваются возможности именно этого варианта термометрии, применительно к геофизическим исследованиям скважин, бурение которых имело гидрогеологическую направленность или преследовало цели обеспечения водоснабжения [3-6].

Среди методов каротажа, применение которых имеет гидрогеологическую направленность, наибольшее использование нашли резистивиметрия и расходометрия, позволяющие выявлять водоактивные интервалы и определять их основные параметры. Несмотря на то, что скважинная термометрия широко и очень успешно используется при контроле за работой скважин на месторождениях нефти и газа, ее применение для 


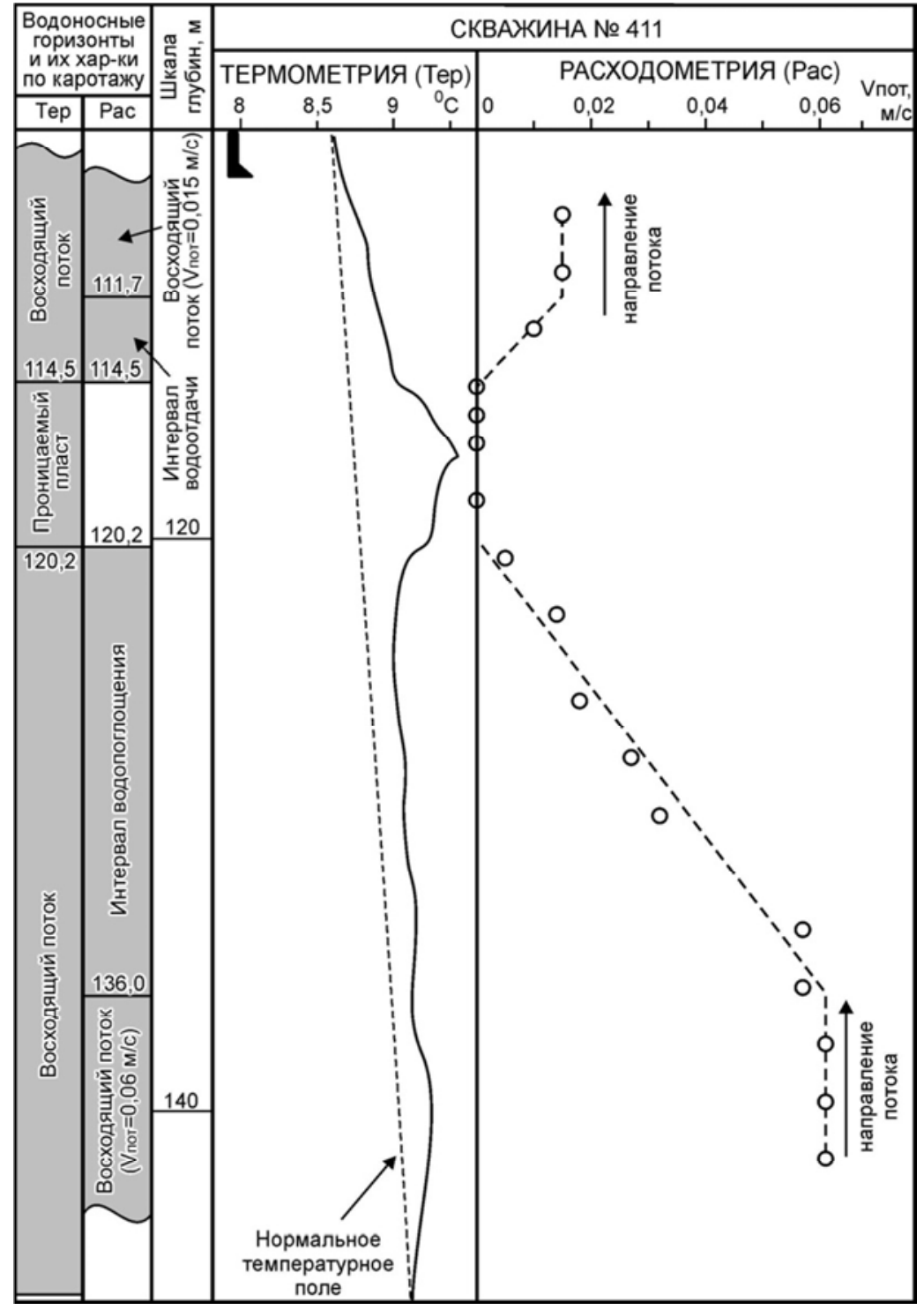

Puc. 1. Результаты расходометрии и термометрии скважины.

ет заметить, что, с относительно недавнего времени, для локализации заколонных перетоков на месторождениях углеводородного сырья стала применяться спектральная шумометрия. Однако по целому ряду причин (высокая стоимость и пр.), метод не скоро будет применяться для обследования «водяных» скважин. Кроме того, термометрия очень чувствительна к слабым вертикальным перетокам, которые не фиксируются тахометрически ми скважинными расходомерами [7-9].

Тепловое поле весьма инерционно, поэтому для расформирования тепловой аномалии образовавшейся в скважине требуется значительное время, которое в общем случае определяется теплофизическими свойствами системы: скважинная жидкость-обсадная колонна-среда, заполняющая заколонное пространство (цементный камень, флюид или воздух) - горные породы. Важно отметить, что часто некоторые элементы системы могут отсутствовать, в частности, в случае необсаженной скважины, система будет включать только два элемента - скважинную жидкость и окружающие скважину горные породы.

Пространственные размеры температурных аномалий, которые часто существенным образом превышают размеры скважины, и величины этих аномалий определяются целым набором факторов. В числе наиболее значимых можно выделить следующие: длительность внешнего температурного воздействия, связанного с работой бурово-

исследования гидрогеологических скважин или контроля работы скважин, используемых для водоснабжения хозяйственных или промышленных объектов, весьма ограничено. Применительно к эксплуатируемым обсаженным скважинам, метод подтвердил свою высокую эффективность при выделении работающих (отдающих и принимающих) интервалов скважины, выявлении заколонных перетоков и внутриколонных перетоков, определении мест негерметичности обсадных колонн.

Необходимо отметить, что в некоторых случаях термометрия позволяет решать задачи, которые не решаются иными геофизическими методами. Одним из наиболее характерных примеров является выявление заколонных перетоков. Поскольку эти потоки циркулируют только в затрубном пространстве и не затрагивают скважинной жидкости, находящейся внутри обсадной колонны, то они не могут быть выявлены расходометрией. Справедливости ради, следу- го инструмента, промывкой скважины и проникновением промывочной жидкости в проницаемые пласты; соотношение температур промывочной жидкости и горных пород; откачка флюидов из пластовколлекторов и переток флюидов между пластами.

На рис. 1 приведен пример сложной температурной аномалии, зарегистрированной в одной из гидрогеологических скважин Тамбовской области после проведения в ней опытной откачки $[3,8]$. Интерпретация материалов скважинной термометрии, выполненная с привлечением данных расходометрии, позволила сделать заключение о наличии двух не связанных между собой направленных вверх перетоков. Эти перетоки разделены находящимся в пределах глубин 114,5 - 120 м слабопроницаемым пластом, который отмечается весьма резкой положительной аномалией температуры. Появление подобной температурной аномалии обусловлено продолжительным проникновением в данный пласт более теплого бурового раствора, 
что привело к увеличению его температуры, в том чисВажно заметить, что бурение исследованной скважины осуществлялось в летнее время года, и буровой раствор готовился на основе воды, взятой из хорошо прогретого водоема. Если бы бурение проводилось зимой, то температурная аномалия против слабопроницаемого пласта была бы отрицательной.

Результаты расходометрии свидетельствуют о наличии в скважине в интервале 107,3-146 м двух восходящих потоков разной интенсивности. При этом в пределах глубин 111,7-114,5 м находится водоотдающий пласт, вода из которого поглощается в локализованном вблизи башмака обсадной колонны, интервале разреза и частично перекрытом обсадной колонной. В интервале 120,0-136,0 м находится водопоглощающий пласт, вода в который поступает с забоя скважины (к моменту проведения расходометрии, из-за обрушения трещиноватых известняков, залегающих выше по разрезу, в скважине образовался искусственный забой).

Комплексный анализ результатов термометрии и расходометрии позволил интерпретировать достаточ- ле и на значительном расстоянии от ствола скважины. но сложные и неоднозначные материалы исследований с высокой степенью достоверности.

Изучение перетоков, направленных вдоль оси скважины, возможно и путем отслеживания положения границы раздела между двумя контрастными жидкостями, различающимися по удельному электрическому сопротивлению, температуре и пр.

Пример выявления затрубной циркуляции и вертикального перетока по стволу скважины показан на рис. 2 [3]. На каротажной диаграмме заколонному перетоку соответствует участок практически постоянной температуры, нисходящему потоку в открытом стволе - интервал хорошо выраженной отрицательной температурной аномалии, а интервалу поглощения отвечает относительно интенсивное нарастание температуры от его кровли к подошве. Башмак обсадной колонны уверенно отмечается локальным градиентным участком.

Положение водопоглощающего интервала в разрезе скважины подтверждается и результатами резистивиметрии, выполнявшейся после засоления скважины,

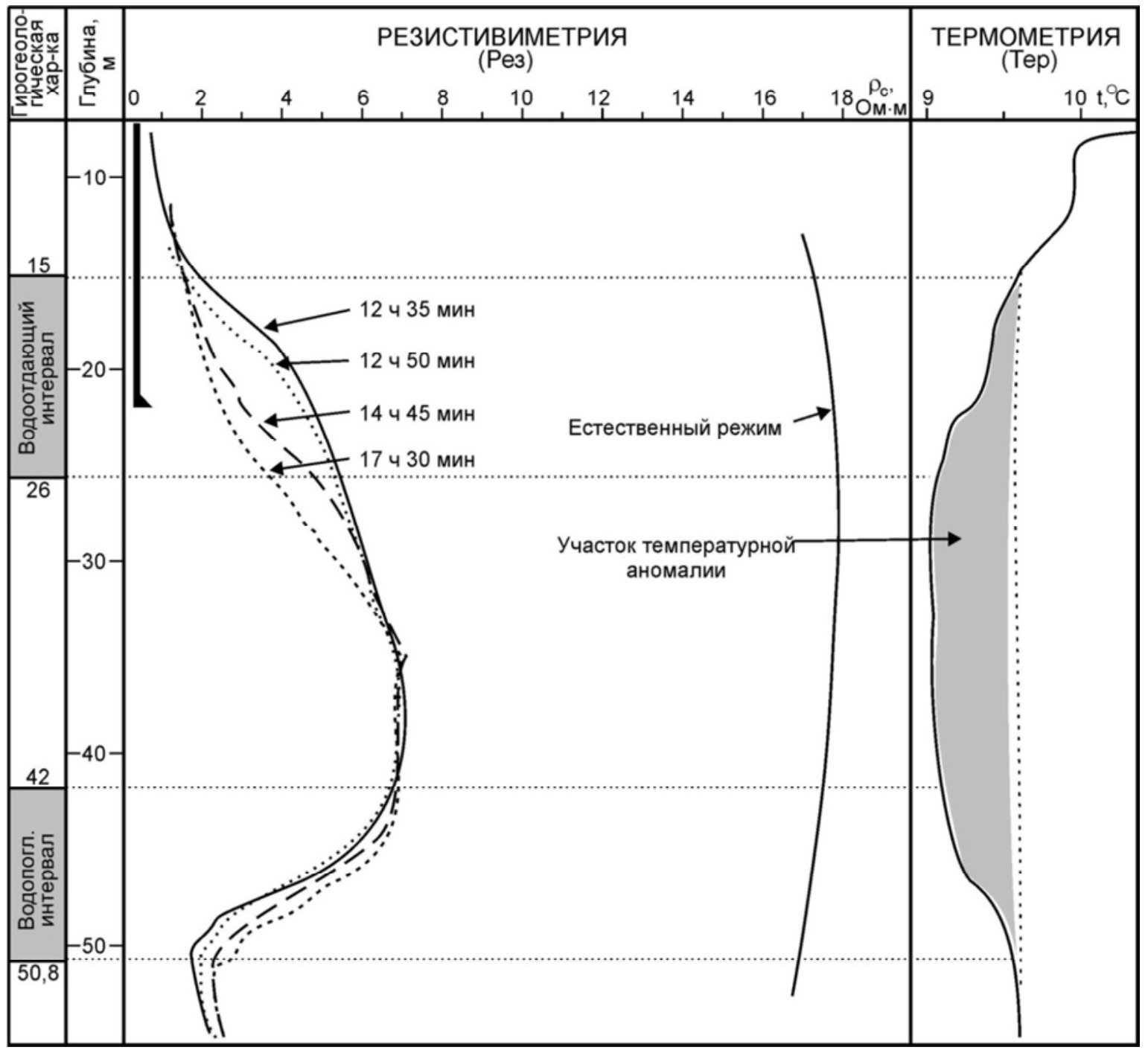

Puc. 2. Выявление затрубной циркуляции и перетока по стволу скважины. 
по данным которой положение контакта пресной и осолоненной воды вблизи отметки 46 м, на протяжении всего цикла измерений (с 12 ч 35 мин до 17 ч 30 мин) остается практически неизменной. Постепенное опускание контакта минерализованной и пресной воды от отметки 17 м до 29 м за 5 часов наблюдений вызвано постепенным понижением уровня скважинной жидкости. Анализ перемещения контакта осолоненной и пресной воды во времени показал, что вертикальная скорость его движения составляла около 2,4 м/ч. Заметим, что эта величина находится вне пределов чувствительности стандартного механического расходомера.

\section{Выводы}

В отношении совершенствования комплекса методов гидрогеологического каротажа, можно рекомендовать включение в его состав термометрии, желательно в комплексе с расходометрией и резистивиметрией. При этом, исследования следует проводить при различных режимах работы скважин - в моменты наливов и откачек, сразу после окончания наливов и откачек, во время восстановления естественного режима и в квазистационарном режиме, после длительного пребывания скважины в состоянии покоя.

Скважинная термометрия способна выявить заколонные перетоки в эксплуатируемый водоносный горизонт вод из неглубоко залегающих водоносных пластов, которые часто имеют поверхностные источники питания и в наибольшей степени подвержены загрязнению.

Температурные измерения весьма эффективны при выявлении антропогенного воздействия на подземные воды, поскольку воздействия такого рода сказываются, прежде всего, на температуре и минерализации вод. Мониторинг этих параметров представляется наиболее эффективным, поскольку позволяет прогнозировать развитие антропогенных процессов и степень их влияния на экологическую ситуацию.

Необходимо обратить внимание на перспективность комплексного изучения температурных характеристик разрезов месторождений подземных вод в целом, когда измерения температуры выполняются во всех доступных для исследования скважинах месторождения в различных режимах их эксплуатации, в том числе и в состоянии покоя. Опыт подобного рода исследований свидетельствует, что такая методика наиболее эффективна при выявлении гидравлических связей между различными водоносными горизонтами и определении их источников питания.

\section{ЛИТЕРАТУРА}

1. Аузин, А. А. Геотермические исследования в скважине 11/89 на учебном геофизическом полигоне Веневитиново / А. А. Аузин // Вестник Воронежского государственного университета. Серия: Геология. - 1999. - № 8. - С. 192 194.

2. Череменский, Г. А. Геотермия / Г. А. Череменский. - Л.: Недра, 1972. - 271 с.

3. Аузин, A. А. Повышение эффективности геофизических исследований в гидрогеологических скважинах в условиях Центрально-Черноземного региона / А. А. Аузин // Вестник Воронежского государственного университета. Серия: Геология. - 1999. - № 7. - С. 196 - 201.

4. Гринбаум, И. И. Геофизические методы определения фильтрационных свойств горных пород / И.И. Гринбаум. М. : Недра, 1965. - 188 с.

5. Мелькановиикий, И. М. Методика геофизических исследований при поисках и разведке месторождений пресных вод / И. М. Мелькановицкий, В. А. Ряполова, М. А. Хордикайнен. - М. : Недра, 1982. - 293 с.

6. Методические рекомендации по применению геофизических исследований в скважинах при проведении гидрогеологических и инженерно-геологических работ / под ред. И. М. Гершановича. - М. : ВСЕГИНГЕО, 1986. - 67 с.

7. Гринбаум, И. И. Расходометрия гидрогеологических и инженерно-геологических скважин / И. И. Гринбаум. - М. : Недра, 1975. - $271 \mathrm{c.}$

8. Аузин, А. А. Комплексирование методов геофизических исследований в скважинах (на примере Воронежской антеклизы) / А. А. Аузин. - Воронеж : Изд-во «Научная книга». 2010. $-260 \mathrm{c.}$

9. Сидоров, B. A. Состояние и развитие геофизических исследований гидрогеологических скважин / В. А. Сидоров, С. А. Калташев, Л. Г. Коротченко. - М. : Изд-во ВСЕГИНГЕО. 1985. $-34 \mathrm{c}$.

\section{ФГБОУ ВО «Воронежский государственный университет»}

Аузин Андрей Альбертович, доктор технических наук, профессор кафедры геофизики геологического факультета E-mail:AAuzin@yandex.ru Тел.: +7 (473) 2208385

Хеляль Марьям Ахмад, Сирийская Арабская Республика, аспирант кафедры геофизики геологического факультета E-mail:maryam.he@hotmail.com Тел.: +7 (473) 2208385

\section{Voronezh State University}

Auzin A. A., the doctor of Technical Science, professor of the Geophysical department of Geological faculty

E-mail: AAuzin@yandex.ru

Tel.: +7 (473) 2208385

Maryam Ahmad Helal, the post-graduate student of the Geophysical department of Geological faculty

E-mail:maryam.he@hotmail.com

Tel.: +7 (473) 2208385 